\begin{tabular}{|c|l|}
\hline Title & A Framework for Facilitating Experiential Learning \\
\hline Author(s) & Matsuo, Makoto \\
\hline Citation & $\begin{array}{l}\text { Human Resource Development Review, 14(4), 442-461 } \\
\text { https://doi.org/10.1177/1534484315598087 }\end{array}$ \\
\hline Issue Date & $2015-12$ \\
\hline Doc URL & http://hdl.handle.net/2115/63746 \\
\hline Type & article (author version) \\
\hline File Information & Self-archiving (HRDR).pdf \\
\hline
\end{tabular}

Instructions for use 


\title{
A Framework for Facilitating Experiential Learning
}

\author{
Makoto Matsuo ${ }^{1}$
}

\begin{abstract}
Although learning from experience is recognized as important for the development of managers, there is no systematic model regarding how to facilitate experiential learning. This study was designed to develop a theoretical framework for the ability to learn from experience. Drawing on the literature, I have developed a model in which five facilitators (seeking challenging tasks, critical reflection, enjoyment of work, learning goal orientation, and developmental network) directly and indirectly facilitate performance of the four steps of Kolb's experiential learning process. The central contribution of this study is to propose a framework that integrates factors that facilitate experiential learning in various fields. The present research compensates for the shortcomings of Kolb's experiential learning cycle.
\end{abstract}

\section{Keywords}

experiential learning, facilitator, work experience, manager development

\section{Introduction}

Work experience is a primary source of manager development (Lombardo \& Eichinger,2010; Morrison \& Brantner, 1992). Facilitating experiential learning in the workplace is essential for developing managers, particularly in the context of providing cross cultural training for expatriate managers (Illeris, 2007; Littrell, Salas, Hess, Paley,

\footnotetext{
1 Hokkaido University, Sapporo, Japan

Corresponding Author:

Makoto Matsuo, Professor of Management, Graduate School of Economics and Business Administration, Hokkaido University, Kita9 Nishi7, Kita-ku, Sapporo city, Hokkaido 060-0809, Japan.

Email:mmatsuo@econ.hokudai.ac.jp
} 
\& Riedel, 2006; McCall \& Hollenbeck, 2002; Yamazaki \& Kayes, 2004, 2007). The field of human resource development (HRD) is currently experiencing a shift from formal training to on-the-job learning (Berings, Poell, \& Simons, 2005), and HRD professionals have attempted to help managers develop managerial skills through work experience (Goldman, 2008).

Previous research has focused primarily on identifying the characteristics of the work experience of successful managers, which is called the "developmental challenge" (DeRue \& Wellman, 2009; Dragoni, Tesluk, Russell, \& Oh, 2009; McCauley, Ruderman, Ohlott, \& Morrow, 1994). However, the establishment of a developmental challenge does not guarantee success because not all people learn equally from the same type of job assignment. To describe the process of individual learning from experience, D. A. Kolb (1984) proposed an experiential learning model, which is one of the most influential and pervasive models in management learning (Armstrong \& Mahmud, 2008; Kayes, 2002; Yamazaki \& Kayes, 2004). However, his model has been criticized because it fails to consider social factors, critical reflection, and the meta-learning process (Holman, Pavlica, \& Thorpe 1997; Reynolds \& Vince, 2004; Vince, 1998).

To better understand experiential learning, the factors that activate the experiential learning process must be specified. Although some authors have reported empirical findings related to the ability to learn from experience (e.g., Spreitzer, McCall, \& Mahoney, 1997), no systematic model for the facilitators of experiential learning exists. Therefore, further investigation and the development of theories about the ability to learn from experience are required.

This article aims to develop a theoretical framework for understanding the factors that facilitate experiential learning based on the literature regarding goal setting, management learning, positive psychology, and mentoring, domains in which the facilitators of individual learning in the workplace have been investigated. This framework may provide insight into the factors that help employees learn from their work experiences. Specifically, it will specify the characteristics related to goal orientation, social networks, attitudes, and behaviors that enhance the quality of experiential learning. The central contribution of this work is to compensate for the shortcomings of D. A. Kolb's (1984) model, which fails to consider social relationships, critical reflection, and goals.

D. A. Kolb's (1984) experiential learning model has been applied in various research fields, as it provides useful insights about how to develop good employees and managers through work experience. Thus, the proposed framework is intended to be relevant to the literature on HRD. 


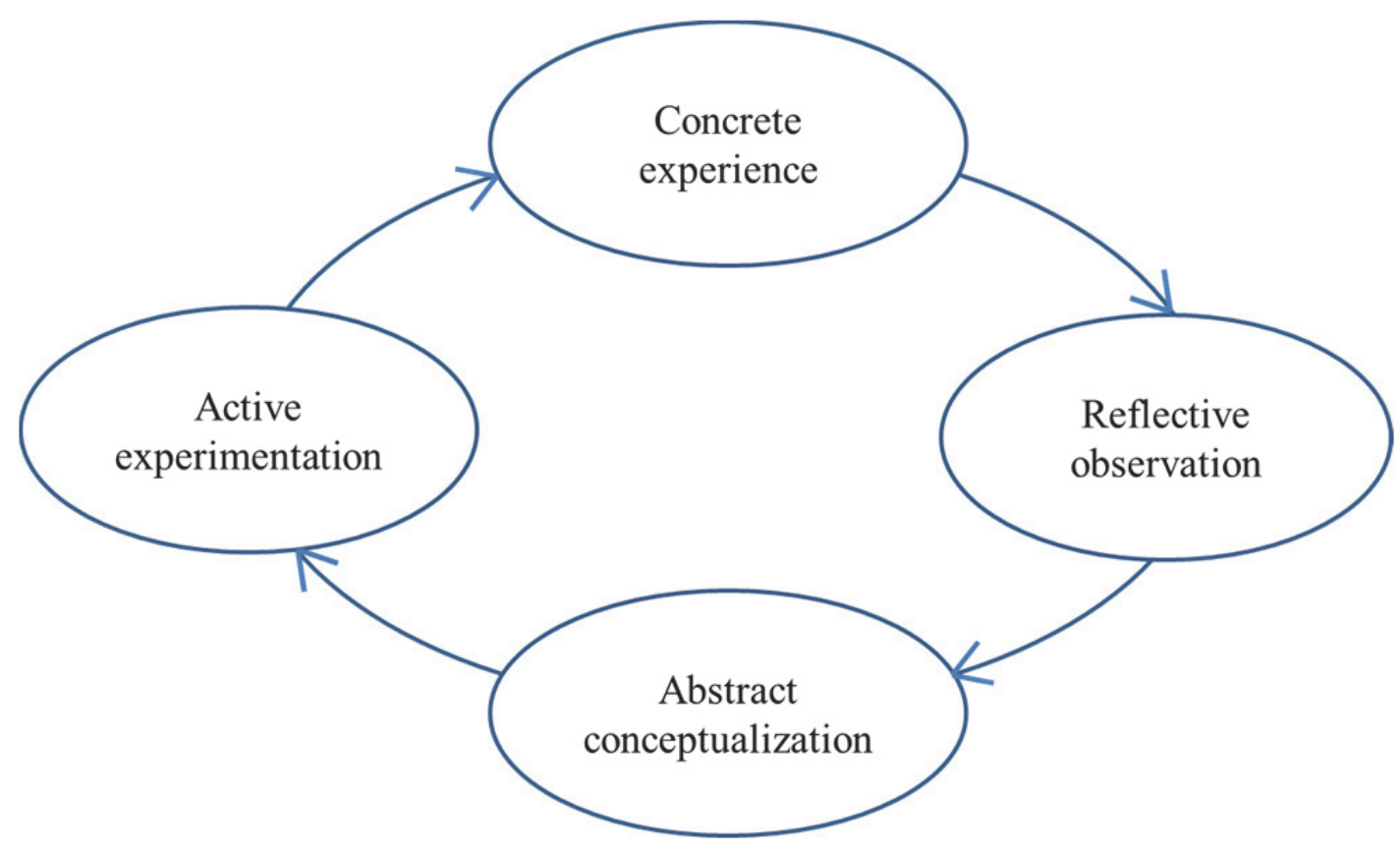

Figure 1. D.A. Kolb's (1984) experiential learning model.

The article is organized as follows. First, the literature regarding the extant theories and empirical studies-related experiential learning are reviewed. Second, a framework for facilitating experiential learning is proposed based on research in several fields. Finally, theoretical and practical implications for future research are discussed.

\section{Literature Regarding Experiential Learning Experiential Learning}

To develop a framework for experiential learning, the concepts of experience and experiential learning must first be clarified. According to Dewey (1938), experience refers to an individual's interaction with his or her external environment, and it is generally defined as events that occur in an individual's life that are perceived by the individual. Work experience is the subset of life events that are most directly and immediately relevant to work attitudes, motivation, and performance (Quinones, Ford, \& Teachout, 1995; Tesluk \& Jacobs, 1998). One important factor distinguishing successful managers from others is the job-related tacit knowledge they learn from work experience (Armstrong \& Mahmud, 2008).

Experiential learning theory is an adult learning theory that highlights the critical role experience plays in learning and change ( $\mathrm{Ng}$, Dyne, \& Ang, 2009). The notion of 
experiential learning has been the main source of inspiration for many people who participate in an attempt to understand the process of learning and education (Illeris, 2007). One of the most influential and pervasive models in management learning is D. A. Kolb's (1984) experiential learning model, which has received considerable empirical support (Kayes, 2002; Vince, 1998; Yamazaki \& Kayes, 2004). As shown in Figure 1, Kolb has proposed a four-stage cyclical model, which consists of the following four stages of experiential learning: (a) concrete experience, (b) reflective observation, (c) abstract conceptualization, and (d) active experimentation. Specifically, immediate personal experience forms the basis for observation and reflection, which can be assimilated into abstract hypotheses or concepts, guiding learners to create new experiences. Individuals need to experience all four stages of learning to gain maximum developmental benefits from work assignments ( $\mathrm{Ng}$ et al., 2009). There have been many studies using this model to advance the theory and practice of experiential learning (A. Y. Kolb \& Kolb, 2005).

Boud, Chen, and Walker (1993) noted that experience is not simply an event that happens; it is an event with meaning. D. A. Kolb's (1984) model suggests that learning is a process where knowledge is created through the transformation of experience. Dixon (1999) also argued that learning is about interpreting one's experience, which affects one's actions.

In their interview research, McCall and his colleagues posed two questions to successful executives: "What happened?" "What did you learn from it (for better or worse)" (McCall \& Hollenbeck, 2002; McCall, Lombardo, \& Morrison, 1988). This procedure indicates that they conceptualized experiential learning as an "event" that is combined with the "lessons" that individuals extract from the event, following Kolb's model. The experiential learning model also offers the theoretical foundation for explaining the association between an individual's skills and knowledge and his or her job experiences (Sims, 1983).

However, D. A. Kolb's (1984) model has been criticized because of its emphasis on the centrality of individual experience at the expense of the psychodynamic, social, political, and institutional aspects of learning (Kayes, 2002; Reynolds \& Vince, 2004; Vince, 1998). Holman et al. (1997) argued that Kolb's model over-emphasizes the individual learning process and that individual learning should be viewed as a process inseparable from the social and historical position of the learner. Reynolds (1998) also argued that reflection in experiential learning theory is qualitatively different from the concept of critical reflection, which involves an analysis of power and control and an examination of the "taken-for-granteds" within which the task or problem is situated. 
Similarly, Vince (1998) pointed out that the experiential learning model is a "first-order" process and that it does not adequately propose a "second-order" or higher meta-learning process, which includes reflection on one's reflections. The critics suggest that experiential learning models should include social factors, critical reflection, and a meta-learning process, which may promote learning from experience.

In addition, although Kolb's model explains how an individual learns from experience, it does not specify the factors that facilitate experiential learning. Specifically, the model fails to clarify the types of experience and reflection that promote individual learning performance. Therefore, a model that includes factors that activate Kolb's experiential learning cycle is needed.

\section{Developmental Work Experience}

Prior empirical studies have focused on the "concrete experience" stage in D. A. Kolb's (1984) learning model, investigating the features of work experiences that promote a manager's development. Davies and Easterby-Smith (1984) asked 60 managers in five different companies to provide their thoughts about their professional development. They found that managers develop their abilities when they are confronted with novelty that forces them to accept major changes in their perspectives, when they make tough decisions and implement them with probity, and when they initiated their developmental process themselves.

McCall and colleagues (McCall, 1998; McCall et al., 1988) also studied successful executives and found that specific experiences that have the most developmental potential can be divided into three categories: (a) job assignments (early work experiences, first supervision, starting from scratch, turnarounds, project/task force, managing a larger scope, and moves from line to staff positions), (b) other people (bosses and role models), and (c) hardships (business mistakes, career setbacks, subordinates with performance problems, changing jobs, and personal trauma). These experiences require managers to acquire skills and knowledge about setting and implementing agendas, handling relationships, establishing basic values, and developing an executive temperament and personal awareness.

Drawing on previous studies, McCauley et al. (1994) developed the Developmental Challenge Profile (DCP) scales, which include five kinds of experience: job transitions, creating change, high levels of responsibility, non-authority relationships, and obstacles. The subsequent empirical studies reported that the developmental challenge was associated with the development of leadership skills (DeRue \& Wellman, 2009) and managerial end-state competencies (Dragoni et al., 2009). 


\section{Ability to Learn From Experience}

Experience may underpin all learning, but it does not always result in learning (Beard \& Wilson, 2002). That is, not all people learn equally from the same kind of experience. Thus, it should be possible to identify specific factors that help employees learn from experience. Some studies have investigated the factors that facilitate experiential learning, and these served as useful references for the framework developed in this article.

To identify international executive potential, Spreitzer et al. (1997) developed a scale to measure the ability to learn from experience, Prospector, which includes endstate competencies (knowledge and skills necessary for effective executive behavior) as well as the ability to learn from experience per se. The scale measuring ability to learn from experience consists of six dimensions: "uses feedback," "is cross-culturally adventurous," "seeks opportunities," "is open to criticism, "seeks feedback," and "is flexible." Results show that being cross-culturally adventurous, seeking opportunities, and being open to criticism predict success with international issues. However, the dimensions of the scale measuring the ability to learn from experience did not have enough predictive power for executive potential beyond the end-state dimensions. Recently, Dragoni et al. (2009) found that the developmental quality of assignments is positively related to managerial end-state competencies when managers have a strong learning goal orientation. These studies indicate that goal orientation works as ability to learn from experience.

Brutus, Ruderman, Ohlott, and McCauley (2000) focused on the role of organization- based self-esteem (OBSE) as the ability to learn from experience. OBSE refers to the self-perceived value and worth of individuals as members of an organization. They found that high-OBSE managers felt they had developed regardless of the characteristics of their jobs, whereas low-OBSE managers felt they had developed only when they had challenging jobs. This suggests that high-OBSE managers have the ability to learn not only from challenging jobs but also from non-challenging jobs.

\section{Summary}

Although there seems to be a consensus among researchers that managers learn through challenging job experiences that force them to explore new things, developmental experiences do not guarantee success (McCall, 1998). Managers need the ability to learn from experience to develop their competencies. Although some researchers have 
examined factors related to the ability to learn from experience, there is no systematic model regarding the factors that facilitate experiential learning.

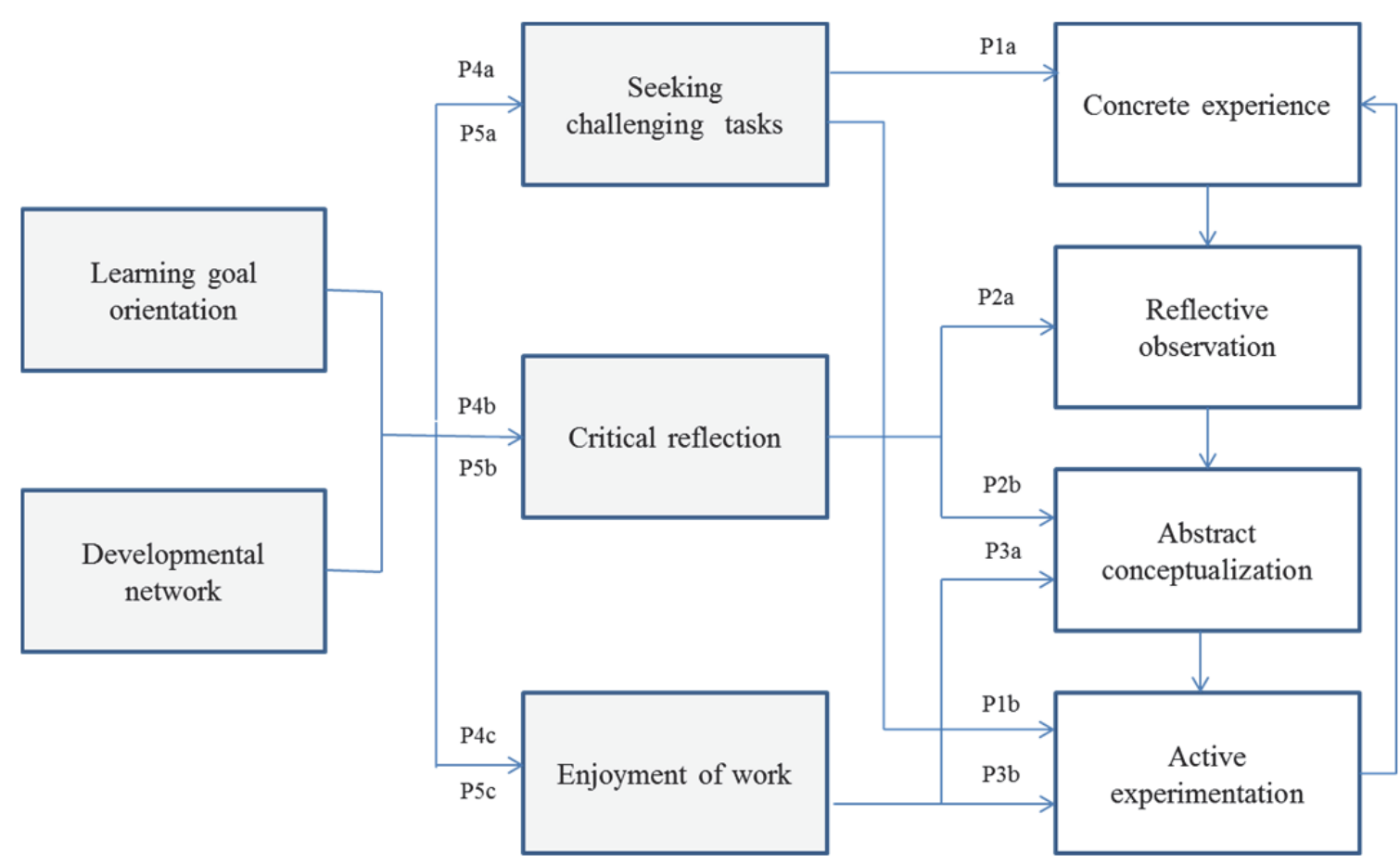

Figure 2. A framework for facilitators of experiential learning.

\section{A Framework for Experiential Learning}

Overview of the Framework

To extend our understanding of how people learn from experience, I propose the causal model for facilitators of experiential learning shown in Figure 2. The framework consists of propositions regarding causal relationships drawn from Kolb's experiential learning process and its facilitators. Specifically, there are three types of attitudes and behaviors (seeking challenging tasks, critical reflection, and enjoyment of work) that have direct impact on the four stages of D. A. Kolb's (1984) experiential learning model (concrete experience, reflective observation, abstract conceptualization, and active experimentation). The framework also assumes that individual goals (learning goal orientation) and social network (developmental network) are antecedents of the three types of attitudes and behaviors that facilitate experiential learning. In the following sections, I explain the framework and propositions in more detail. 


\section{Seeking Challenging Tasks}

Previous research on managers' experiential learning has consistently reported that challenging experience, or developmental challenge, facilitates managers' learning (McCall, 1998; McCall et al., 1988; McCauley, Moxley, \& Velsor, 1998). Specifically, experiences such as unfamiliar responsibilities, creating change, high levels of responsibility, working across boundaries, and managing diversity promote the learning and performance of managers (McCauley et al., 1994; DeRue \& Wellman, 2009; Dragoni et al., 2009). Having challenging experiences is closely related to the steps of "concrete experience" and "active experimentation" in D. A. Kolb's (1984) experiential learning model. The problem here is that Kolb's model fails to specify the factors that enhance the quality of experience.

Challenging experience promotes learning because individuals confront novel situations and problems for which their existing repertoire of behaviors is inadequate, and they have to develop new ways of dealing with these situations (Davies \& EasterbySmith, 1984). De Pater, Van Vianen, Bechtoldt, and Klehe (2009) also reported that confronting challenging experiences is important to receiving favorable supervisory and formal organizational promotability evaluations.

The importance of seeking challenging tasks is emphasized in the research on goal setting and expertise. Based on empirical studies, Locke and Latham (1990) stated that challenging and specific goals encourage individuals to exert more effort and to optimize their task strategies, which in turn leads to improved performance beyond their current level. Locke and Latham (2002) also argued that there is a positive, linear function in that the highest or most difficult goals produced the highest levels of effort and performance. Although their research is primarily concerned with goals set by external agents, previous research indicates that the same mechanisms can be applied to self-set goals (Keith \& Ericsson, 2007).

In their expertise research, Ericsson, Krampe, and Tesch-Romer (1993) introduced the concept of deliberate practice to describe focused and effortful practice activities with the explicit goal of performance improvement. Deliberate practice refers to training activities that include a well-defined task with an appropriate difficulty level for a particular individual, informative feedback, and opportunities for repetition and error correction (Ericsson, 1996, 2004; Ericsson et al., 1993). This practice can be applied not only to training by coaches or supervisors but also to self-directed learning activities. According to empirical studies in several domains including music, sports, and chess, the amount of accumulated deliberate practice is closely associated with an individual's attained level of performance (Keith \& Ericsson, 2007). The research on deliberate 
practice suggests that individuals can learn from experience by engaging in challenging tasks at appropriate levels of difficulty.

As mentioned above, challenging experiences force individuals to acquire new skills and knowledge and apply them to situations. To enhance the quality of experience and promote active experimentation, learners need to proactively seek challenging tasks. Thus, the following propositions are offered:

Proposition 1a: Seeking challenging tasks positively affects the quality of concrete experience.

Proposition 1b: Seeking challenging tasks positively affects active experimentation.

\section{Critical Reflection}

Challenging experience does not always result in learning. Experiential learning theory emphasizes the role of the individual in constructing meaning from experiences, the experiences in which he or she is engaged (Goldman, 2008). As D. A. Kolb's (1984) model suggests, reflection is necessary to gain lessons from the experience. Reflection is a key component of learning, yet managers tend to place a higher value on action than reflection (Daudelin, 1996). Mirvis (2008) insisted that programs of executive development should include "consciousness-raising experiences" designed to open the minds and hearts of executives and stimulate reflection on their lives, their work, and their companies.

However, Kolb's model does not clarify the type of reflection that facilitates learning and abstract conceptualization. It is important to distinguish between "reflection" that just examines the meaning of our experience and "critical reflection" that critiques the presuppositions on which beliefs are built (Gray, 2007). Cunliffe (2004) explained the distinction using the concept of single-loop and double-loop learning proposed by Argyris (1991). Specifically, single-loop learning (problem solving, identifying, and correcting errors) corresponds to reflection, whereas double-loop learning (thinking more critically about behavior; questioning assumptions, values, and espoused theories; disconfirming, inventing, producing, and evaluating new theories in action) is equivalent to critical reflection. Similarly, Reynolds (1998) argued that critical reflection that involves an examination of the taken-for-granteds within which the task or problem is situated is qualitatively different from the concept of reflection that focuses on the immediate, presenting details of a task or problem. Cunliffe (2009) also stated that self-reflexivity, dialogue-with-self about fundamental assumptions, values, and ways of interacting, enables us to become responsive to others 
and open to the possibilities for new ways of being and acting.

The concept of reflective practice introduced by Schön (1983) also stresses critical reflection. Reflective practice refers to the practice of periodically stepping back to consider the meaning of what recently transpired to others and to oneself in one's immediate environment (Raelin, 2002). One of the functions of reflective practice is to explore other ways of seeing, and it adopts an attitude of inquiry rather than determining answers based solely on positional authority (Yanow \& Tsoukas, 2009). Cunliffe (2004) argued that critically reflexive practice contains subjective understandings of reality as a basis for thinking more critically about the impact of our assumptions, values, and actions on others. Reflection on one's own premises can lead to transformative learning (Mezirow, 1990). Spreitzer et al. (1997) also discussed being "open to criticism" as one of the dimensions of the ability to learn from experience. They found that being "open to criticism" was significantly related to behavioral skill learning.

Critical reflection is not required for all types of experiential learning, especially those involved in routine tasks. However, when employees engage in non-routine or creative tasks, critical reflection on what was experienced leads to the identification of new ways of being and acting. In addition, it is possible that employees who reflect on Downloaded from hrd.sagepub.com at KOBE UNIV on December 10, 2015450 Human Resource Development Review 14(4) their work critically can perform even their routine tasks in a creative way. Therefore, the following propositions are offered:

Proposition 2a: Critical reflection positively affects the quality of reflective observation.

Proposition 2b: Critical reflection positively affects the quality of abstract conceptualization.

\section{Enjoyment of Work}

The third step of Kolb's learning model is "abstract conceptualization" in which lessons and the meaning of events are extracted through reflective experiences. This step is critical for advancement to the fourth step, which is "active experimentation." To keep on engaging in challenging tasks, we need enjoyment of work. Enjoyment of work is the degree to which individuals work because they find the work itself intrinsically interesting or pleasurable (Graves, Ruderman, Ohlott, \& Weber, 2012; Spence \& Robbins, 1992). Amabile (1988) stated that people will be most creative when they are primarily intrinsically motivated by the interest, enjoyment, satisfaction, and challenge of the work itself. Graves et al. (2012) found that enjoyment of work was positively 
related to career satisfaction and performance and negatively related to the psychological strain of managers and stated that being motivated by enjoyment of work is critical for managerial effectiveness and well-being.

Enjoyment of work is closely associated with "flow experience" (Csikszentmihalyi, 1975, 1990). According to Rodríguez-Sánchez, Schaufeli, Salanova, Cifre, and Sonnenschein (2011), flow consists of three elements: enjoyment (the positive feeling of enjoyment while being engaged in the activity), intrinsic interest (the interest in performing the activity for its own sake and not because of external demands or pressures), and absorption (a sense of deep involvement and total concentration). Using survey data, they reported that healthy individuals experienced more flow than nonhealthy (burned-out) individuals. Specifically, healthy individuals who were neither on sick leave nor suffered from mental or physical illness tended to enjoy and be engrossed in what they were doing.

Research on intrinsic motivation and flow experience are included in "positive psychology," or the study of the conditions and processes that contribute to the flourishing or optimal functioning of people, groups, and institutions by focusing on positive human functioning, including well-being, contentment, satisfaction hope, optimism, flow, and happiness (Gable \& Haidt, 2005; Seligman \& Csikszentmihalyi, 2000). Positive psychology underscores the recognition and development of human potential as opposed to simply focusing on those with problems (Macaskill \& Denovan, 2013). As this field was introduced as a way to promote the study of psychological characteristics presumed to benefit well-being (McNulty \& Fincham, 2012), enjoyment of work is treated as an important facilitator of experiential learning.

It should be noted that enjoyment of work is not always necessary for learning, and people are often extrinsically motivated to learn from experience. However, the propensity to enjoy work may facilitate experiential learning without extrinsic rewards. When we enjoy working, we are engaged, interested, and involved in the activities. Such psychological sets enable us to extract profound lessons from work experiences and motivate us to apply the lessons in subsequent situations. Thus, the following propositions are offered:

Proposition 3a: Enjoyment of work positively affects abstract conceptualization.

Proposition 3b: Enjoyment of work positively affects active experiment.

\section{Learning Goal}

Seeking challenging tasks, critical reflection, and enjoyment of work may have direct 
impacts on performance learning, but what promotes these three facilitators? One of the antecedents that may influence the three elements of the ability to learn from experience is goal orientation, which refers to one's preferences in an achievement situation (Payne, Youngcourt, \& Beaubien, 2007).

Dweck and her colleague classified goal orientation into a performance goal, where the purpose is to validate one's ability or avoid demonstrating a lack of ability, and learning goals, where the aim is to acquire new knowledge or skills (Dweck, 1986; Grant \& Dweck, 2003). Early conceptualization of goal orientation was performed by educational psychologists who observed classroom situations, whereas several studies have considered goal orientation in relation to job performance. Most of the latter reported a positive relationship between a learning goal orientation and performance outcomes (Potosky, 2010). Because a learning goal guides the individual's behavior (Dweck \& Leggett, 1988), it may be regarded as meta-cognitive knowledge, which is consistent with implicit person theory (Heslin, Vandewalle, \& Latham, 2006).

Previous research suggests that a learning orientation is associated with adaptive response patterns in achievement situations and is characterized by challenge seeking, persistence, acquisition of knowledge, and mastery of uncertain environments. However, a performance orientation underlies a maladaptive response pattern characterized by an avoidance of challenge and a deterioration in performance in the face of obstacles (Dweck \& Leggett, 1988; Porter, Webb, \& Gogus, 2010).

For example, using a sample of unemployed job seekers, Noordzij, Van Hooft, Van Mierlo, Van Dam, and Born (2013) found that job seekers with a high learning goal orientation tended to learn from failure and employ a strategy involving awareness to accomplish their goals during the job-search process. Based on meta-analytic research, Payne et al. (2007) stated that individuals with a strong learning goal orientation are inclined to set more difficult goals because they tend to be interested in learning for its own sake and often view achievement situations as a challenge. Therefore, the following proposition is offered:

Proposition 4a: Learning goal orientation positively affects seeking challenging tasks.

Unlike those individuals with a performance goal orientation who try to avoid demonstrating a lack of ability, individuals with a strong learning goal orientation may critically reflect on their activities to identify weaknesses requiring improvement because they are intrinsically motivated to acquire new knowledge and skills. For 
example, Runhaar, Sanders, and Yang (2010) reported that teachers' learning goal orientation has a positive impact on their reflection and sharing feedback. The results suggests that when a teacher's goal is to improve competencies and to complete new and more complex tasks, he or she is more willing to engage in learning activities involving reflection and seeking feedback. As individuals with a learning goal orientation are concerned with acquiring new knowledge and skills, they may be eager to learn lessons by critically reflecting on their own experiences. Therefore, the following proposition is offered.

Proposition 4b: Learning goal orientation positively affects critical reflection.

Empirical studies on goal orientation also report that the adoption of a learning goal is presumed to lead to a mastery motivational pattern involving enhanced task enjoyment (Dweck \& Leggett, 1988; Elliot \& Church, 1997). For example, based on the survey research of undergraduate students, Lee, Sheldon, and Turban (2003) reported that mastery goals, or learning goals, are positively related to class enjoyment. As employees with a learning goal orientation are intrinsically motivated to acquire new knowledge or skills, they may seek task enjoyment by enhancing learning at work. Therefore, the following proposition is offered:

Proposition 4c: Learning goal orientation positively affects enjoyment of work.

\section{Developmental Network}

The other antecedent that may influence the three facilitators (seeking challenging tasks, critical reflection, and enjoyment of work) is developmental network, which is defined as groups of people who take an active interest in and action toward advancing a protégé's (mentee's) career (Dobrow, Chandler, Murphy, \& Kram, 2011). In other words, the developmental network is conceptualized as an egocentric, or self-perceived, constellation of interactive developers inside and outside of a focal person's employing organization that provides career and/or psychosocial support through relationships of varying strength (Cotton, Shen, \& Livne-Tarandach, 2011). Higgins and Kram (2001) referred to individuals who provide developmental assistance as "developers."

Mentoring and social network researchers often refer to a number of constructs that are almost interchangeable with developmental networks, including multiple mentors, mentoring networks, intra-organizational networks, core discussion networks, and interpersonal networks (Dobrow et al., 2011; Molloy, 2005). 
The developmental support that mentors provide to mentees can be conceptualized as vocational support (coaching, protecting, and offering challenging assignments), psychosocial support (acceptance and confirmation, counseling, and friendship), and role modeling (Kram, 1983; Pellegrini \& Scandura, 2005). Individuals who have a developmental network can receive support from mentors.

The mentors also help mentees enhance self-efficacy and promotability by providing protection and challenging assignments (de Janasz, Sullivan, \& Whiting, 2003). Higgins (2001) reported that the range of an individual's set of psychological advice relationships was related to his or her confidence in overcoming career obstacles.

It should be noted that many developmental networks may be embedded in communities of practice, which are defined as groups of people who share their knowledge and expertise in a given area by interacting on an ongoing basis (Wenger, McDermott, \& Snyder, 2002). Interactions in these communities may provide members with growth opportunities. For example, using a survey of electronic communities of practice, Wasko and Faraj (2000) found that participation in the community is challenging, helps refine members' thinking, and contributes to the development of new insights. This suggests that developmental networks in communities of practice are sources of challenging tasks. In view of the vocational functions of mentoring in communities, an individual with developmental networks may confront challenging tasks and seek advice to achieve the tasks. Therefore, the following proposition is offered:

Proposition 5a: Developmental network positively affects seeking challenging tasks.

Spreitzer et al. (1997) pointed out that seeking feedback is among the abilities involved in learning from experience. Essential feedback from developers may promote the reflection of mentees. For example, based on case studies of teachers, Sempowicz and Hudson (2012) demonstrated that the mentors' personal attributes influenced the mentoring relationship and the mentees' abilities to critically reflect on their practices. Nakamura and Yorks (2011) also stated that reflective practices and social capital can be productively interrelated with each other. In addition, Ghosh, Haynes, and Kram (2013) suggested that the developers in the developmental network play important roles in encouraging leaders to practice critical reflection, which can reframe the views and frameworks used in decision making. Therefore, the following proposition is offered: 
Proposition 5b: Developmental network positively affects critical reflection.

The psychosocial support, including acceptance and confirmation, counseling, and friendship, provided by developers may help mentees enjoy their work. Past research indicates that having developers who come from outside one's work organization is linked with career and life satisfaction (Murphy \& Kram, 2010). Wasko and Faraj (2000) reported that participation in the community of practice is fun because participants enjoy

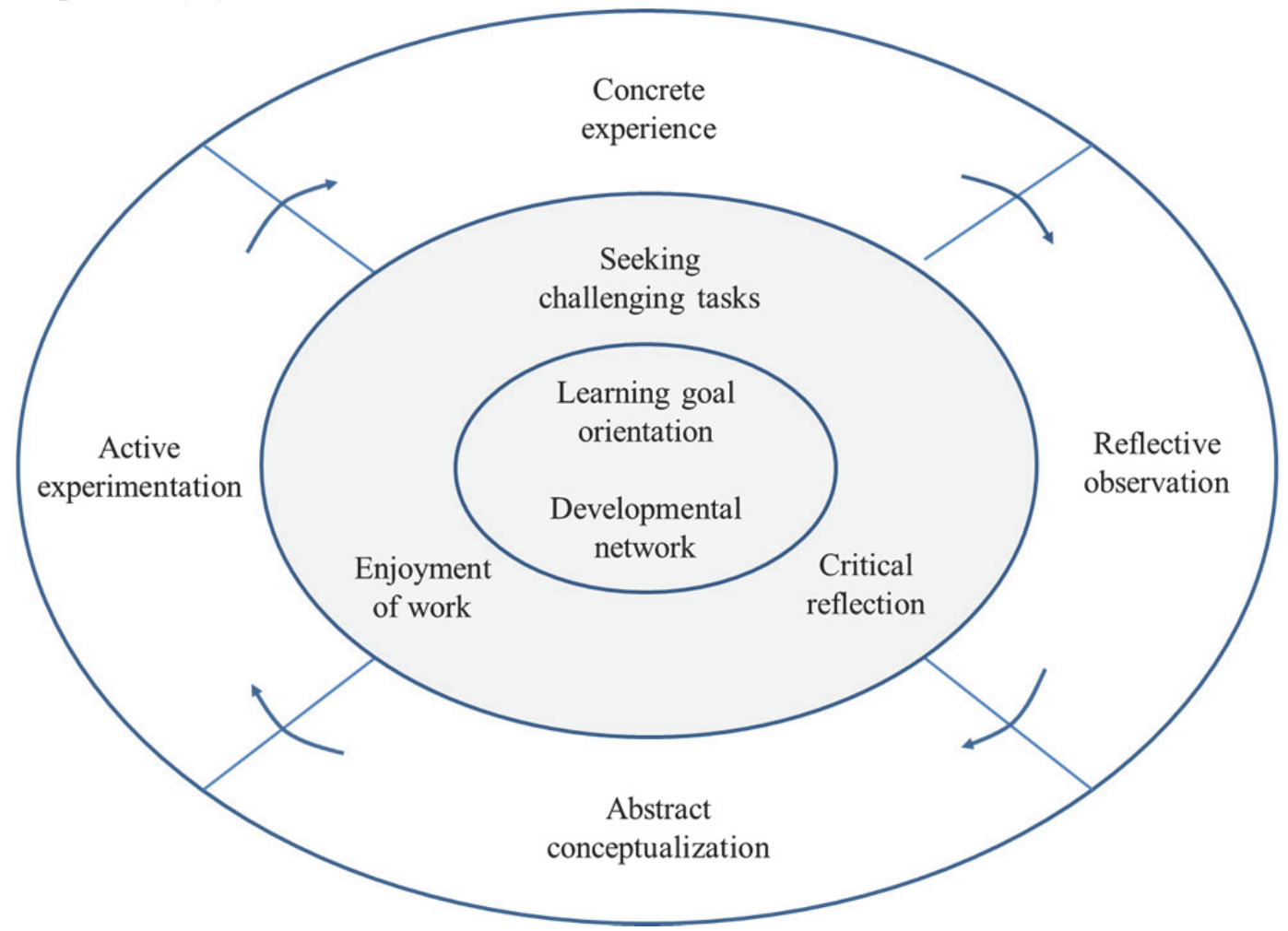

Figure 3. Experiential learning cycle and its facilitators.

learning and sharing with others. This suggests that people who are linked with developmental networks in communities tend to enjoy learning in the workplace. Thus, the following proposition is offered:

Proposition 5c: Developmental network positively affects enjoyment of work.

\section{Implications for Research and Management}

\section{Theoretical Implications}

D. A. Kolb's (1984) experiential learning cycle is one of the most influential models in 
management learning research. Although Kolb's model describes the process of experiential learning (Kayes, 2002), the model does not include factors that help individuals learn from experience. It is necessary for HRD professionals to understand the factors that facilitate experiential learning so that they can design effective HRD systems. Figure 3 presents the conceptual model based on the aforementioned propositions and suggests that two-layer facilitators contribute to the achievement of the four stages of Kolb's experiential learning process.

The theoretical implications of this study can be summarized as follows. First, the central contribution of this study is to propose a framework that integrates the factors that facilitate experiential learning across various fields, including management learning, goal setting, mentoring, and positive psychology, based on D. A. Kolb's (1984) experiential learning model. The framework proposed here is a complementary model that compensates for shortcomings in Kolb's model.

Second, one of the unique characteristics of this framework is that goal orientation and developmental network are positioned as drivers that activate three facilitators of experiential learning. Kolb's model has been criticized for failing to consider social factors and meta-learning processes (Holman et al., 1997; Reynolds \& Vince, 2004; Vince, 1998). The proposed framework in this article complements Kolb's model by including developmental network as a social factor and goal orientation as a meta-cognitive knowledge factor that guides human cognitive activities (Nelson \& Narens, 1994). As mentioned above, managers gain learning opportunities through challenging tasks, critical feedback, and encouragement by means of developmental networks. Learning goal orientation motivates managers to seek challenging tasks, critically reflect on their experience, and experience the enjoyment of personal growth. The framework of this study suggests that the ability to learn from experience has a multilayered structure.

Third, a set of testable research propositions are presented that may serve as a stimulus for future empirical research. Collectively, these contributions may further conceptual and empirical understanding concerning the ability to learn from experience. Most of the variables in propositions can be measured by existing scales that have already been used in empirical studies. It will be interesting to identify the relative influence of "seeking challenging tasks," "critical reflection," and "enjoyment of work" on learning performance. In addition, an interesting question is how the developmental network interacts with goal orientation in promoting experiential learning. Prior empirical studies on mentoring (e.g., Dragoni \& Kuenzi, 2012; Egan, 2005) suggest that developmental network could have an impact on individual goal orientation. It is also 
likely that individuals with high learning goal orientation could create developmental networks because such persons may attract mentors who would like to provide developmental support. Future research might be directed toward understanding how an individual's goal orientation is mutually associated with his or her developmental network.

Finally, it is also important to investigate the relationship among three facilitators (seeking challenging tasks, critical reflection, and enjoyment of work). One might expect that the three facilitators are associated with one another. For instance, seeking challenging tasks may facilitate reflective practice because we need to reconsider our way of thinking and acting to achieve challenging tasks. Conversely, reflective practice may lead to seeking challenging tasks because reflecting on our fundamental assumptions may encourage us to seek a new way of doing and acting (Cunliffe, 2009; Yanow \& Tsoukas, 2009). Similarly, there might be a close interaction between critical reflection and enjoyment of work and between enjoyment of work and seeking challenging tasks. By qualitatively and quantitatively studying the relationships among seeking challenging tasks, critical reflection, and enjoyment of work, we can obtain a deeper insight into the mechanisms underlying the ability to learn from experience.

\section{Practical Implications}

The findings suggest that HRD professionals can help managers develop the ability to learn from experience in several ways. First, the framework presented here can be used as a tool for the early identification of future executives. As future demands may include some skills and knowledge that are different from those valued today, the ability to learn from experience may be more important in the long run than a high rating in a currently valued competency (Spreitzer et al., 1997). Thus, candidates for managerial positions should be assessed and recruited in terms of the framework proposed in this article. Specifically, it is possible to assess candidates' attitudes and behaviors (seeking challenging tasks, critical reflection, and enjoyment of work), learning goal orientation, and their networks using $360^{\circ}$ appraisal systems. The assessment results can be used to identify the potential of future executives.

Second, experiential training programs for developing managers (Littrell et al., 2006; McGuire \& Gubbins, 2010) should be designed to enhance the ability to learn from experience. In particular, training programs enhancing critical reflection might play an important role in activating the ability to learn from experience because it is important for us to critically reflect on the assumptions underlying our goals, network, tasks, and sources of enjoyment, which may be difficult to confront. 
Third, HRD professionals should periodically assess the learning capabilities of members using surveys based on this framework. Many competency surveys focusing on end-state competencies are insufficient because they cannot predict personal development in the future. To activate on-the-job learning in the workplace, managers need to pay attention to members' abilities to learn from experience.

Finally, it is necessary for HRD professionals to focus not only on individual capabilities but also on their network with others when assessing their ability to learn from experience. As the framework of this article suggests, an individual's developmental network may influence his or her goals, attitudes, and behaviors. Therefore, HRD professionals should help members and students create developmental or mentoring networks by providing them with opportunities to interact with key persons in their own or other organizations.

\section{Conclusion}

Although some authors have reported empirical findings regarding the ability to learn from experience, there is no systematic model on the facilitators and inhibitors of experiential learning. The central contribution of this article is to clarify the facilitators of experiential learning by integrating and extending theoretical concepts and empirical findings that have not traditionally been combined. The framework proposed in this study is complementary in that it compensates for shortcomings in D. A. Kolb's (1984) experiential learning model. Future qualitative and quantitative research should examine and test the framework proposed herein.

\section{Declaration of Conflicting Interests}

The author(s) declared no potential conflicts of interest with respect to the research, authorship, and/or publication of this article.

\section{Funding}

The author(s) disclosed receipt of the following financial support for the research, authorship, and/or publication of this article: This work was supported by JSPS KAKENHI Grant Numbers 26285078.

\section{References}

Amabile, T. M. (1988). A model of creativity and innovation in organizations. In B. M. Staw \& L. L. Cummings (Eds.), Research in organizational behavior (Vol. 10, pp. 123-167). Greenwich, CT: JAI Press. 
Argyris, C. (1991, May-June). Teaching smart people how to learn. Harvard Business Review, 69(3), 99-109.

Armstrong, S. J., \& Mahmud, A. (2008). Experiential learning and the acquisition of managerial tacit knowledge. Academy of Management Learning \& Education, 7, 189-208.

Beard, C., \& Wilson, J. P. (2002). The power of experiential learning: A handbook for trainers and educators. London, England: Kogan Page.

Berings, M. M. C., Poell, R. F., \& Simons, P. R. (2005). Conceptualizing on-the-job learning styles. Human Resource Development Review, 4, 373-400.

Boud, D., Chen, R., \& Walker, D. (1993). Using experience for learning. Buckingham, UK: SRHE and Open University Press.

Brutus, S., Ruderman, M. N., Ohlott, P. J., \& McCauley, C. D. (2000). Developing from job experiences: The role of organization-based self-esteem. Human Resource Development Quarterly, 11, 367-380.

Cotton, R. D., Shen, Y., \& Livne-Tarandach, R. (2011). On becoming extraordinary: The content and structure of the developmental network of major league baseball hall. Academy of Management Journal, 54, 15-46.

Csikszentmihalyi, M. (1975). Beyond boredom and anxiety. San Francisco, CA: Jossey-Bass.

Csikszentmihalyi, M. (1990). Flow: The psychology of optimal experience. New York, NY: Harper \& Row.

Cunliffe, A. L. (2004). On becoming a critically reflexive practitioner. Journal of Management Education, 28, 407-426.

Cunliffe, A. L. (2009). The philosopher leader: On relationalism, ethics and reflexivity: A critical perspective to teaching leadership. Management Learning, 40, 87-101.

Daudelin, M. W. (1996). Learning from experience through reflection. Organizational Dynamics, 24(3), 36-49.

Davies, J., \& Easterby-Smith, M. (1984). Learning and developing from managerial work experiences. Journal of Management Studies, 21, 169-183.

de Janasz, S. C., Sullivan, S. E., \& Whiting, V. (2003). Mentor networks and career success: Lessons for turbulent times. Academy of Management Executive, 17(4), 78-91.

De Pater, I. E., Van Vianen, A. M., Bechtoldt, M. N., \& Klehe, U. (2009). Employees' challenging job experiences and supervisors' evaluations of promotability. Personnel Psychology, 62, 297-325.

DeRue, D. S., \& Wellman, N. (2009). Developing leaders via experience: The role of 
developmental challenge, learning orientation, and feedback availability. Journal of Applied Psychology, 94, 859-875.

Dewey, J. (1938). Experience and education. Indianapolis, IN: Kappa Delta Pi.

Dixon, N. M. (1999). The organizational learning cycle: How we can learn collectively ( $2^{\text {nd }}$ ed.). Brookfield, VT: Gower.

Dobrow, S. R., Chandler, D. E., Murphy, W. M., \& Kram, K. E. (2011). A review of developmental networks: Incorporating a mutuality perspective. Journal of Management, 38, 210-242.

Dragoni, L., \& Kuenzi, M. (2012). Better understanding work unit goal orientation: Its emergence and impact under different types of work unit structure. Journal of Applied Psychology, 97, 1032-1048.

Dragoni, L., Tesluk, P. E., Russell, J. A., \& Oh, I. (2009). Understanding managerial development: Integrating developmental assignments, learning orientation, and access to developmental opportunities in predicting managerial competencies. Academy of Management Journal, 52, 731-743.

Dweck, C. S. (1986). Motivational processes affecting learning. American Psychologist, 41, 1040-1048.

Dweck, C. S., \& Leggett, E. L. (1988). A social-cognitive approach to motivation and personality. Psychological Review, 95, 256-273.

Egan, T. M. (2005). The impact of learning goal orientation similarity on formal mentoring relationship outcomes. Advances in Developing Human Resources, 7, 489-504.

Elliot, A. J., \& Church, M. A. (1997). A hierarchical model of approach and avoidance achievement motivation. Journal of Personality and Social Psychology, 72, 218-232.

Ericsson, K. A. (1996). The acquisition of expert performance: An introduction to some of the issues. In K. A. Ericsson (Ed.), The road to excellence (pp.1-50). Mahwah, NJ: Lawrence Erlbaum.

Ericsson, K. A. (2004). Deliberate practice and the acquisition and maintenance of expert performance in medicine and related domains. Academic Medicine, 79(10), S70-S81.

Ericsson, K. A., Krampe, R., \& Tesch-Romer, C. (1993). The role of deliberate practice in the acquisition of expert performance. Psychological Review, 100, 363-406.

Gable, S. L., \& Haidt, J. (2005). What (and why) is positive psychology? Review of General Psychology, 9, 103-110.

Ghosh, R., Haynes, R. K., \& Kram, K. E. (2013). Developmental networks at work: 
Holding environments for leader development. Career Development International, $18,232-256$.

Goldman, E. F. (2008). The power of work experiences: Characteristics critical to developing expertise in strategic thinking. Human Resource Development Quarterly, $19,217-239$.

Grant, H., \& Dweck, C. S. (2003). Clarifying achievement goals and their impact. Journal of Personality and Social Psychology, 85, 541-553.

Graves, L. M., Ruderman, M. N., Ohlott, P. J., \& Weber, T. J. (2012). Driven to work and enjoyment of work: Effects on managers' outcomes. Journal of Management, $38,1655-1680$.

Gray, D. E. (2007). Facilitating management learning: Developing Critical reflection through reflective tools. Management Learning, 38, 495-517.

Heslin, P. A., Vandewalle, D., \& Latham, G. P. (2006). Keen to help? Managers' implicit person theories and their subsequent employee coaching. Personnel Psychology, 59, 871-902.

Higgins, M. C. (2001). Changing careers: The effect of social context. Journal of Organizational Behavior, 22, 595-618.

Higgins, M. C., \& Kram, K. E. (2001). Reconceptualizing mentoring at work: A developmental network perspective. Academy of Management Review, 26, 264-288.

Holman, D., Pavlica, K., \& Thorpe, R. (1997). Rethinking Kolb's theory of experiential learning: The contribution of social constructivism and activity theory. Management Learning, 28, 135-148.

Illeris, K. (2007). What do we actually mean by experiential learning? Human Resource Development Review, 6, 84-95.

Kayes, D. C. (2002). Experiential learning and its critics: Preserving the role of experience in management learning and education. Academy of Management Learning \& Education, 1, 137-149.

Keith, N., \& Ericsson, K. A. (2007). A deliberate practice account of typing proficiency in everyday typists. Journal of Experimental Psychology: Applied, 13, 135-145.

Kolb, A. Y., \& Kolb, D. A. (2005). Learning styles and learning spaces: Enhancing experiential learning in higher education. Academy of Management Learning \& Education, 4, 193-212.

Kolb, D. A. (1984). Experiential learning: Experience as the source of learning and development. Englewood Cliffs, NJ: Prentice Hall.

Kram, K. E. (1983). Phases of the mentoring relationship. Academy of Management Journal, 26, 608-625. 
Lee, F. K., Sheldon, K. M., \& Turban, D. B. (2003). Personality and the goal-striving process: The influence of achievement goal patterns, goal level, and mental focus on performance and enjoyment. Journal of Applied Psychology, 88, 256-265.

Littrell, L. N., Salas, E., Hess, K. P., Paley, M., \& Riedel, S. (2006). Expatriate preparation: A critical analysis of 25 years of cross-cultural training research. Human Resource Development Review, 5, 355-388.

Locke, E. A., \& Latham, G. P. (1990). A theory of goal setting and task performance. Englewood Cliffs, NJ: Prentice Hall.

Locke, E. A., \& Latham, G. P. (2002). Building a practically useful theory of goal setting and task motivation: A 35-year odyssey. American Psychologist, 57, 705-717.

Lombardo, M. M., \& Eichinger, R. W. (2010). The career architect: Development planner (5th ed.). Minneapolis, MN: Lominger International.

Macaskill, A., \& Denovan, A. (2013). Developing autonomous learning in first-year university students using perspective from positive psychology. Studies in Higher Education, 38, 124-142.

McCall, M. W. (1998). High flyers: Developing the next generation of leaders. Boston, MA: Harvard Business School Press.

McCall, M. W., \& Hollenbeck, G. P. (2002). Developing global executives: The lessons of international experience. Boston, MA: Harvard Business School Press.

McCall, M. W., Lombardo, M. M., \& Morrison, A. M. (1988). The lessons of experience: How successful executives develop on the job. New York, NY: Free Press.

McCauley, C. D., Moxley, R. S., \& Velsor, E. V. (1998). The center for creative leadership: Handbook of leadership development. New York: Jossey-Bass.

McCauley, C. D., Ruderman, M. N., Ohlott, P. J., \& Morrow, J. E. (1994). Assessing the developmental components of managerial jobs. Journal of Applied Psychology, 79, 544-560.

McGuire, D., \& Gubbins, C. (2010). The slow death of formal learning: A polemic. Human Resource Development Review, 9, 249-265.

McNulty, J. K., \& Fincham, F. D. (2012). Beyond positive psychology? Toward a contextual view of psychological processes and well-being. American Psychologist, 67, 101-110.

Mezirow, J. (1990). How critical reflection triggers transformative learning. In J. Mezirow (Ed.), Fostering critical reflection in adulthood: A guide to transformative and emancipatory learning (pp. 1-20). San Francisco, CA: Jossey-Bass. 
Mirvis, P. (2008). Executive development through consciousness-raising experiences. Academy of Management Learning \& Education, 7, 173-188.

Molloy, J. C. (2005). Development networks: Literature review and future research. Career Development International, 10, 536-547.

Morrison, R. F., \& Brantner, T. M. (1992). What enhances or inhibits learning a new job? A basic career issue. Journal of Applied Psychology, 77, 926-940.

Murphy, W. M., \& Kram, K. E. (2010). Understanding non-work relationships in developmental networks. Career Development International, 15, 637-663.

Nakamura, Y. T., \& Yorks, L. (2011). The role of reflective practices in building social capital in organizations from an HRD perspective. Human Resource Development Review, 10, 222-245.

Nelson, T. O., \& Narens, L. N. (1994). Why investigate metacognition? In J. Metcalfe \& A. P. Shimamura (Eds.), Metacognition: Knowing about knowing (pp.1-25). Cambridge, MA: MIT Press.

Ng, K., Dyne, L. V., \& Ang, S. (2009). From experience to experiential learning: Cultural intelligence as a learning capability for global leader development. Academy of Management Learning \& Education, 8, 511-526.

Noordzij, G., Van Hooft, E. A. J., Van Mierlo, H., Van Dam, A., \& Born, M. P. (2013). The effects of a learning-goal orientation training on self-regulation: A field experiment among unemployed job seekers. Personnel Psychology, 66,723-755.

Payne, S. C., Youngcourt, A. A., \& Beaubien, J. M. (2007). A meta-analytic examination of the goal orientation nomological net. Journal of Applied Psychology, 92, 128-150.

Pellegrini, E. K., \& Scandura, T. A. (2005). Construct equivalence across groups: An unexplored issue in mentoring research. Educational and Psychological Measurement, 65, 323-335.

Porter, C. O. L. H., Webb, J. W., \& Gogus, C. I. (2010). When goal orientations collide: Effects of learning and performance orientation on team adaptability in response to workload imbalance. Journal of Applied Psychology, 95, 935-943.

Potosky, D. (2010). Goal orientation, learning self-efficacy, and climate perceptions in a postacquisition corporate context. Human Resource Development Quarterly, 21, 273-289.

Quinones, M. A., Ford, J. K., \& Teachout, M. S. (1995). The relationship between work experience and job performance: A conceptual and meta-analytic review. Personnel Psychology, 48, 887-910.

Raelin, J. A. (2002). “I don't have time to think!" versus the art of reflective practice. 
Reflections, 4(1), 66-79.

Reynolds, M. (1998). Reflection and critical reflection in management learning. Management Learning, 29, 183-200.

Reynolds, M., \& Vince, R. (2004). Organizing reflection: An introduction. In M. Reynolds \& R. Vince (Eds.), Organizing reflection (pp.1-14). Aldershot: Ashgatel Gower.

Rodríguez-Sánchez, A. M., Schaufeli, W., Salanova, M., Cifre, E., \& Sonnenschein, M. (2011). Enjoyment and absorption: An electronic diary study on daily flow patterns. Work \& Stress, 25, 75-92.

Runhaar, P., Sanders, K., \& Yang, H. (2010). Stimulating teachers' reflection and feedback asking: An interplay of self-efficacy, learning goal orientation, and transformational leadership. Teaching and Teacher Education, 26, 1154-1161.

Schön, D. A. (1983). The reflective practitioner: How professionals think in action. New York, NY: Basic Books.

Seligman, M. E. P., \& Csikszentmihalyi, M. (2000). Positive psychology: An introduction. American Psychology, 55, 5-14.

Sempowicz, T., \& Hudson, P. (2012). Mentoring pre-service teachers' reflective practices towards producing teaching outcomes. International Journal of Evidence Based Coaching \& Mentoring, 10(2), 52-64.

Sims, R. R. (1983). Kolb's experiential learning theory: A framework for assessing person-job interaction. Academy of Management Review, 8, 501-508.

Spence, J. T., \& Robbins, A. S. (1992). Workaholism: Definition, measurement, and preliminary results. Journal of Personality Assessment, 58, 160-178.

Spreitzer, G. M., McCall, M. W., \& Mahoney, J. D. (1997). Early identification of international executive potential. Journal of Applied Psychology, 82(1), 6-29.

Tesluk, P. E., \& Jacobs, R. R. (1998). Toward an integrated model of work experience. Personnel Psychology, 51, 321-355.

Vince, R. (1998). Behind and beyond Kolb's learning cycle. Journal of Management Education, 22, 304-319.

Wasko, M. M., \& Faraj, S. (2000). "It is what one does": Why people participate and help others in electronic communities of practice. Journal of Strategic Information Systems, 9, 155-173.

Wenger, E., McDermott, R., \& Snyder, W. M. (2002). Cultivating communities of practice: A guide to managing knowledge. Boston, MA: Harvard Business School Publishing.

Yamazaki, Y., \& Kayes, D. C. (2004). An experiential approach to cross-cultural 
learning: A review and integration of competencies for successful expatriate adaptation. Academy of Management Learning \& Education, 3, 362-379.

Yamazaki, Y., \& Kayes, D. C. (2007). Expatriate learning: Exploring how Japanese managers adapt in the United States. International Journal of Human Resource Management, 18, 1373-1395.

Yanow, D., \& Tsoukas, H. (2009). What is reflection-in-action? A phenomenological account. Journal of Management Studies, 46, 1339-1364.

\section{Author Biography}

Makoto Matsuo is a professor at Hokkaido University. His interests are in experiential learning and human resource development. 